\title{
Bileşik Kesitli Kanallarda Debi Hesabı
}

\author{
Mustafa MAMAK ${ }^{1}$, Hatice Betül UMARUSMAN ${ }^{1}$, Yunus Ziya KAYA*1 \\ ${ }^{\text {I} O s m a n i y e ~ K o r k u t ~ A t a ~ U ̈ n i v e r s i t e s i, ~ M u ̈ h e n d i s l i k ~ F a k u ̈ l t e s i, ~ I ̇ n s ̧ a a t ~ M u ̈ h e n d i s l i g ̆ i ~ B o ̈ l u ̈ m u ̈, ~}$ \\ Osmaniye
}

Geliş tarihi: 06.02.2017 Kabul tarihi: 31.05.2017

$\ddot{\mathbf{O} z}$

Bir ana kanal ve taşkın yataklarından oluşan bileşik kesitli kanallarda birçok debi hesaplama yöntemi mevcuttur. Bu çalışmada, klasik yöntemlerden olan SCM (Tek Kanal Metodu) ve DCM (Bölünmüş Kanal Metodu) yöntemleri kullanılarak debi hesaplaması yapılmıştır. Literatürde verilen bileşik kesitli bir kanala uygulanan bu yöntemler ile yapılan hesaplamalar sonucunda elde edilen hesap debileriyle deneysel debi değerleri karşılaştırılmış ve bu klasik yöntemlerin geçerliliği incelenmiştir.

Anahtar Kelimeler: Bileşik kesitli kanal, Tek Kanal Metodu (SCM), Bölünmüş Kanal Metodu (DCM)

\section{The Computation of Discharge Capacity in Compound Channels}

\begin{abstract}
There are many computation methods for the discharge capacity of compound channels consisting of a main channel and its floodplains. In this study, the discharge computation is carried out using Single Channel Method (SCM) and Divided Channel Method (DCM) known as classical methods. These methods have been applied to a compound channel given in literature. The computed discharge values were compared with the experimental discharge values, and the validity of these classical methods is investigated.
\end{abstract}

Keywords: Compound channel, Single Channel Method (SCM), Divided Channel Method (DCM)

\footnotetext{
*Sorumlu yazar (Corresponding author): Yunus Ziya KAYA, yunuszkaya@osmaniye.edu.tr
} 


\section{GíRiș}

Bileşik kesitli kanallar, ana yatak ve taşkın yatağ veya yataklarından oluşan önemli su yapılarıdır. Taşkın sırasında meydana gelebilecek zararları önlemesi bu yapıların önemini arttırmaktadır. Taşkın yatakları ana kanalların taşıma kapasitesini arttırmasına yardımcı olurlar.

Seçkin [1], laboratuvardaki geniş ve küçük ölçekli kanallardan ve prototip bir bileşik nehir kanalından (Main River) elde edilen verilere bir boyutlu Tek Kanal Metodu (SCM), Bölünmüş Kanal Metodu (DCM), Ackers Metodu (COHM) ve Debi Değişim Metodu (EDM) yöntemlerini uygulamıştır. Bu çalışmalarda, taşkın yatakları için düz veya pürüzlü yüzeyler ve ana kanal için rijit veya hareketli yüzeyler incelenmiştir. Seçkin [1], EDM ve COHM'nin diğer metotlardan daha iyi sonuçlar verdiği sonucuna varmıştır.

Rice [2] ve Posey [3] bileşik kesitli kanallarda debi hesaplamaları için geleneksel metotları uygulamışlardır. Kesiti, değişik hayali ara yüzey düzlemler (düşey, yatay, diyagonal) kullanarak hidrolik olarak homojen bölgelere bölmüşlerdir. Her bir bölgenin debisi ayrı ayrı olarak hesaplanmış ve daha sonra toplam debi bulunmuştur. Momentum transfer mekanizması varlığını ihmal ederek, bu metotlara ilişkin hataları ayrı ayrı hesaplamışlardır.

James ve Brown [4], kanalın belli şekil özellikleri ile ilgili sınır pürüzlülügüne dayanan Manning denklemi için basit bir düzeltme faktörü belirlemişlerdir. Metotlarını, "modifiye edilmiş tek kanal" yaklaşımı olarak adlandırmışlar ve hesaplanmış debilerin deneylerde gözlenmiş debilere çok yakın olduğunu tespit etmişlerdir.

Myers [5], ana kanal ve taşkın yatakları akımlarının doğru olarak modellemesinin zorluklarını içeren bileşik kanallarda debi değerlendirme problemlerini araştırmıştır. Teorik hesaplamalar, bileşik kesitli bir kanalda ana kanal hız ve debisinin taşkın yatağı hız ve debisine oranlarının, taban eğiminden bağımsız olduğunu ve sadece derinlik ve geometriden etkilendiğini göstermiştir. $\mathrm{Bu}$ teorik hesaplamaların deneysel sonuçlarla doğrulanmasını, üç simetrik bileşik kesitli kanal düzeneğinden elde edilen veriler kullanılarak gerçekleştirmiştir. Myers, ana kanal ile taşkın yatakları arasındaki etkileşimi ihmal eden geleneksel metotlarla elde edilen değerlerle ölçülmüş debilerin karşılaştırmalarını ve oluşan hataları çalışmasında vermiştir.

Tokyay [6], düşey ara yüzeyler için bir Manning pürüzlülük katsayısı ve daha sonra ana kanal için eşdeğer bir pürüzlülük katsayısı elde etmiştir. Eşdeğer pürüzlülük katsayısının belirlenmesi, pürüzlü taşkın yatakları için SIV (düşey dâhil edilmiş kesit) performansını geliştirmiştir.

Strum ve Sadiq [7], deneysel olarak bir bileşik kanalda birden fazla kritik derinliğin oluşumunu araştırmışlardır.

Myers ve arkadaşları [8], taşkın yatağının pürüzlü/pürüzsüz durumu ile birlikte ana kanalın sabit ve hareketli yüzeylere sahip olması durumundaki deney sonuçlarını incelemişlerdir. Matematiksel modele dayanan, ana kanaldan savaklanan akımlarda debinin belirlenmesine yardımcı olacak hız ve debi oran eşitlikleri sunmuşlar ve elde ettikleri sonuçları prototip doğal bir bileşik kesitli nehir kanalından alınan verilerle karşılaştırmışlardır.

Ana kanal ve taşkın yatağı hızlarının ve debi oranlarının, laboratuvar sonuçları için logaritmik, doğal nehir verileri için ise lineer bir dağılıma sahip olduğunu göstermişlerdir. Bölünmüş Kanal Metodunun (DCM, Divided Channel Method), bütün durumlarda debiyi olduğundan daha fazla tahmin ettiğini vurgulamışlardır. Pürüzsüz taşkın yataklı kanal verilerine uygulandığında makul sonuçlar sergilediğini, fakat pürüzlü taşkın yataklı kanallarda ise hata miktarının \%35'e kadar çıktığını, nehir verilerinde ise hatanın \%27'ye kadar ulaştığını göstermişlerdir. Tek Kanal Metodunun (SCM, Single Channel Method), düşük akım derinliklerinde bütün durumlar için bileşik kanal debisini olduğundan daha düşük tahmin ettiğini, fakat yüksek akım derinliklerinde, nehir verilerinin yanında pürüzsüz yüzeyli laboratuvar kanal sonuçları için de daha gerçekçi sonuçlar verdiğini belirtmişlerdir. 
Atabay ve Knight [9], simetrik bileşik kanal kesiti için bazı seviye debi eşitlikleri vermişlerdir. Taşkın yatağı genişliğinin ve ana kanal en-boy oranının seviye debi ilişkisine etkisini araştırmışlardır. Seviye-toplam debi arasında ve seviye-lokal debi arasında, üniform pürüzlülük ve taşkın yatağı genişlik oranının değişmesi durumları için basit deneysel eşitlikler vermişlerdir. Taşkın yatağı genişlik oranından dolayı seviye-debi ilişkisindeki genel etkileri araştırmışlardır.

Cebe [10], farklı girişim alanları yaklaşımlarına göre taşkın yatağı bulunduran bileşik kesitli kanallarda debi hesap yöntemlerini irdelemiştir. Bileşik kanal debi hesaplarında kullanılan yaklaşımlar için gerekli olan düşey, yatay ve diyagonal girişim yüzeylerinde oluşan kayma gerilmelerinin ana kanal ortalama ve taban kayma gerilmelerine oranını hesaplamıştır. Bu oranlara ve yapılan debi hesaplarına dayanarak bileşik kesitlerde debi hesabı için farklı girişim yüzeyi kabullerini de kapsayan öneriler getirmiştir.

Özbek ve arkadaşları [11], değişken taşkın yatak genişlikli simetrik bileşik kesitli kanallarda, debi ve kayma gerilmesini hesaplamak için sınırlı miktarda veri kullanmışlardır. Ana kanal-taşkın yatakları arasındaki ara yüzeyde oluşan kayma gerilmelerini hesaplamak için ana kanal ile taşkın yatakları arasında farazi üç ara yüzey düzlemini (düşey, yatay ve diyagonal) göz önüne almışlardır. Her bir alt bölge ve toplam kesit için debileri belirlemişlerdir. Hesaplama metodunun performansını, kayma gerilmesini doğru olarak tahmin edebilmesine dayandırmışlardır. Diyagonal ve yatay bölme düzlemli metotların düşey bölme düzlemli metottan daha iyi sonuç verdiğini ve en iyi sonucu ise diyagonal düzlemli metodun verdiğini belirtmişlerdir.

Bu çalışmada, Tek Kanal Yöntemi (SCM) ve ana kanal ile taşkın yatakları arasında farklı ara yüzey düzlemlerine sahip Bölünmüş Kanal Yöntemi (DCM) literatürde verilmiş olan bileşik kanal kesitlerine uygulanmıştır. Yöntemlerin ortalama mutlak hata değerleri incelenmiş ve seviye-debi ilişkileri grafik olarak sunulmuştur.

\section{BİLEŞİK KESITTLİ KANALLARDA DEBİ HESAPLAMA YÖNTEMLERİ}

Bileşik kesitli kanallarda debi hesaplanması için bazı metotlar geliştirilmiştir. Bu kısımda, klasik metotlardan Tek Kanal Metodu (SCM) ve Bölünmüş Kanal Metodu (DCM)'ndan bahsedilecektir.

Bir ana kanal ve taşkın yatağından oluşan bir bileşik kanalın geometrisi Şekil 1'de görülmektedir. Burada $H$, kanal tabanı üzerindeki su derinliğini; h, ana kanal üst kotunun üzerindeki su derinliğini; $\mathrm{B}$, taşkın yatağının ana kanala en uzak noktası ile ana kanal orta noktası arasındaki mesafeyi ve $b$, taşkın yatağının ana kanala en yakın noktası ile ana kanal orta noktası arasındaki mesafeyi göstermektedir.

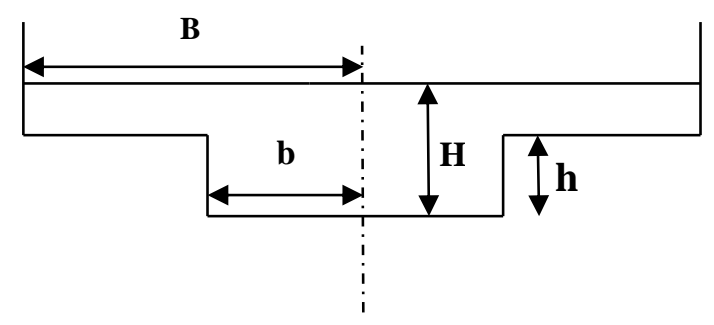

Şekil 1. Bileşik kanal geometrisi

\subsection{Tek Kanal Metodu (SCM)}

Manning [12], yaptığı araştırmalar sonucunda ortalama akım U için Eşitlik 1'de verilen formülü önermiştir:

$U=\frac{R^{2 / 3} S_{0}^{1 / 2}}{n}$

Burada, U ortalama akım hızı; R, en kesit hidrolik yarıçapı (kesit alanı A'nın ıslak çevre P 'ye oranı); $\mathrm{S}_{\mathrm{o}}$, kanal taban eğimini belirtmektedir.

Belli bir seviyedeki debinin hesaplanabilmesi için verilen formül ise Eşitlik 2'de gösterilmiştir.

$Q=A . U=A \frac{R^{2 / 3} S_{0}^{I / 2}}{n}$

Burada Q, debiyi ve $\mathrm{n}$, Manning pürüzlülük katsayısını belirtmektedir. 
Eşitlik 2'nin kullanımı, kanal genişliği boyunca üniform hı dağılımına sahip kanallarla sınırlandırılmalıdır. Denklem, kanalı bir bütün olarak göz önüne almaktadır. Bundan dolayı, bütün en kesit için belirlenmiş olan tek bir pürüzlülük değeri gerekmektedir. Sonuç olarak; SCM, hız dağılımı genellikle üniform olmayan bileşik kanal debi hesaplamaları için uygun değildir. Bileşik kanallarda, ana kanalın ortalama hızı; daha derin kesit ve daha düşük pürüzlülükten dolayı taşkın yataklarındaki ortalama hızdan daha büyüktür. Ayrıca SCM, ana kanal ve taşkın yatakları arasındaki herhangi bir momentum transferini hesaba katmamakta ve genellikle debiyi daha düşük tahmin etmektedir. Buna ilaveten; $\mathrm{SCM}$, tüm en kesit için tek bir eşdeğer pürüzlülük değeri kullanmadıkça, ana kanaldan daha pürüzlü bir taşkın yatağına sahip kesitlerin debisinin hesaplanmasında uygun değildir [13].

$\mathrm{Su}$, taşkın yatakları üzerinde akmaya başladığı anda, kesit alanında küçük bir artıs olmasına karşı1lık 1slak çeperde ani bir artış olur ve bundan ötürü hidrolik yarıçap azalır ve düşük bir debi hesaplanmasına yol açar. Bu yüzden, Lotter [14] gibi birçok araştırmacı, kanal en kesitinin, hızların daha homojen olduğu alt bölgelere bölünmesini önermiştir.

\subsection{Bölünmüş Kanal Metodu (DCM)}

Adından da anlaşıldığı üzere DCM, kanalın birden fazla alanlara bölünmesiyle meydana gelir. Bölünmüş olan bu alanların debileri ayrı ayrı hesaplanır ve tüm kesit debisi, Eșitlik 3 'te gösterildiği üzere debiler toplanarak elde edilmektedir.

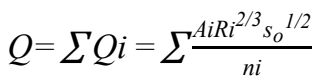

Sellin [15], DCM'nin, ana kanaldaki akımı azaltan, taşkın yataklarındaki akımı hızlandıran yanal momentum değişimini hesaba katmadığından, bileşik kanallarda debiyi olduğundan fazla tahmin ettiğini göstermiştir. Ana kanaldaki akımın geciktirici etkilerini hesaba katmak için, sslak çeper bazen düşey bölme hatlarının dâhil edilmesiyle değiștirilir. Bileşik kanallarda akım mekanizmasında gözlendiği gibi, akım hızlanmış olabileceğinden taşkın yatakları bölgeleri için bu durum geçerli değildir.

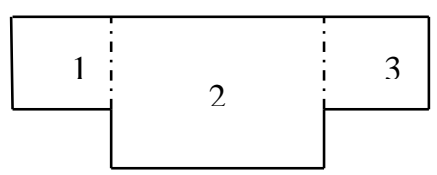

a) Düşey Bölme Hatları

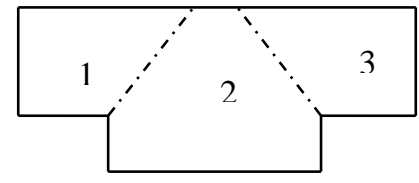

b) Diyagonal Bölme

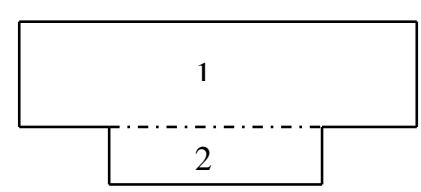

c)Yatay Bölme Hatt1

Şekil 2. Bölünmüş kanal metodu (DCM)

Yen ve Overton [16], Şekil 2 (b)'de gösterildiği gibi en iyi bölme hattının kayma gerilmesinin sıfir olduğu yer olduğunu önermişlerdir. Eş hız eğrilerinden alınan verilere dayanarak sıfır kayma hatlarının diyagonal üzerinde olduğunu tespit etmişlerdir. Bu sıfır kayma hatları, momentum alışverişinin minimum olduğu bölgelere karşılık gelmektedir. $\mathrm{Bu}$ özel bölme metodunun dezavantajı, sıfır kayma hatlarının her su derinliği için belirlenmesi ve bu yüzden ilave bir parametre olarak belirlenmesi gereken diyagonal açısının olmasidır.

Myers [17], Şekil 2 (c)'de tanımlandığı gibi her bir alt bölgenin momentum denge analizini gerçekleştirmiştir. Bir "fiktif kayma gerilmesi" formunda yatay bölme hattında, taşkın yatağı ve ana kanal arasında momentum transferini ifade etmiştir. Fiktif kayma gerilmesini ifade etmek için çeşitli deneysel formüller geliştirilmiştir. Fakat Knight ve Shiono [18]'ya göre, her bir formül belli bir geometri için özgün ve bu yüzden diğer verilere bu formülleri uygulamak zordur. 
Knight ve arkadaşları [19], DCM için belli bir derinlikte debiyi oldukça iyi tahmin edebilmesine rağmen taşkın yataklarında ve ana kanaldaki toplam debinin yüzdesinin doğru olmayabileceğini belirtmişlerdir. Aslında, Wormleaton ve Hadjipanos [20], hesaplanan kesit debilerindeki hatanın \% 60 gibi yüksek bir değere ulaşabileceğini göstermişlerdir.

\section{BULGULAR}

Yukarıda bahsedilen modellerden SCM ve DCM metotlar1 $b=0,144 m, B=0,604 m$ ve $h=0,12 m$ boyutlarına sahip bir bileşik kanal üzerinde dört farklı pürüzlülük (seri $\mathrm{A}, \mathrm{B}, \mathrm{C}, \mathrm{D}$ ) durumlarında uygulanmıştır [21]. A, B, C ve D serileri için taşkın yataklarında farklı Manning $\mathrm{n}$ değerleri kullanılmış ve bu değerler sırasıyla $0,011,0,014$, 0,017 ve 0,021 'dir.

DCM (Bölünmüş Kanal Metodu) yöntemi bileşik kesitli kanala Düşey Bölme Hatları (V), Diyagonal Bölme Hatları (D) ve Yatay Bölme Hatları (H) dâhil edilerek ve dâhil edilmeden debiler ayrı ayrı hesaplanmış ve bunun sonucunda elde edilen hata değerleri Çizelge 1'de verilmiştir. Dahil edilen hatlar alt indis $i$, edilmeyen hatlar ise alt indis e ile gösterilmiştir. Hata payı aşağıda gösterilen Eşitlik 4 ile hesaplanmıştır:

Hata payl $=100 \times\left|\frac{\text { Qhesap-Qdeney }}{\text { Qdeney }}\right|$

Çizelge 1. DCM metoduyla elde edilen hata değerleri (\%)

\begin{tabular}{|c|c|c|c|c|c|c|}
\hline Seri & Vi & Ve & Hi & He & Di & De \\
\hline A & 7,3 & 6,4 & 11,6 & 5,6 & 22,1 & 4,2 \\
\hline B & 7,9 & 14,3 & 9,6 & 4,6 & 18,2 & 6,1 \\
\hline C & 14,6 & 25,5 & 10,6 & 7,9 & 13,1 & 13,1 \\
\hline & 29,4 & 43,3 & 18,8 & 17,6 & 14,2 & 26,5 \\
\hline Ort. & 14,8 & 22,38 & 12,65 & $\mathbf{8 , 9 3}$ & 16,9 & 12,48 \\
\hline
\end{tabular}

Bileşik kanal kesitine DCM yöntemi uygulanarak hesap debileri elde edilmiş ve bu debilerle deneysel debiler karşılaştırılarak en az hata değerini veren yöntem He (yatay bölme hatları dahil edilmeyen) olduğu görülmüştür.

Bileşik kesite, diğer bir yöntem olan SCM (Tek Kanal Metodu)'nin uygulanması sonucunda elde edilmiş hesap debileriyle deneysel debiler karşılaştırılmış ve hata değerleri hesaplanmıştır. $\mathrm{SCM}$ ve $\mathrm{DCM}(\mathrm{He})$ yöntemleri ile bulunan hata değerlerinin karşılaştırılması Çizelge 2'de verilmiştir.

Çizelge 2. SCM ve DCM hata değerleri (\%)

\begin{tabular}{|c|c|c|}
\hline Seri & SCM & $\mathbf{D C M}(\mathbf{H e})$ \\
\hline A & 8,5 & 5,6 \\
\hline B & 1,5 & 4,6 \\
\hline C & 2,3 & 7,9 \\
\hline D & 8,1 & 17,6 \\
\hline Ort. Hata & $\mathbf{5 , 1}$ & 8,9 \\
\hline
\end{tabular}

Çizelge 2'de görüldüğü üzere SCM yöntemiyle elde edilen ortalama hata oranı DCM (He) yöntemiyle elde edilen hata oranından daha azdır.

SCM ve DCM (He) yöntemlerinin yukarıdaki bahsedilen bileşik kesite uygulanması sonucu elde edilen seviye-debi ilişkileri grafik olarak Şekil 3-6'da sunulmuştur.

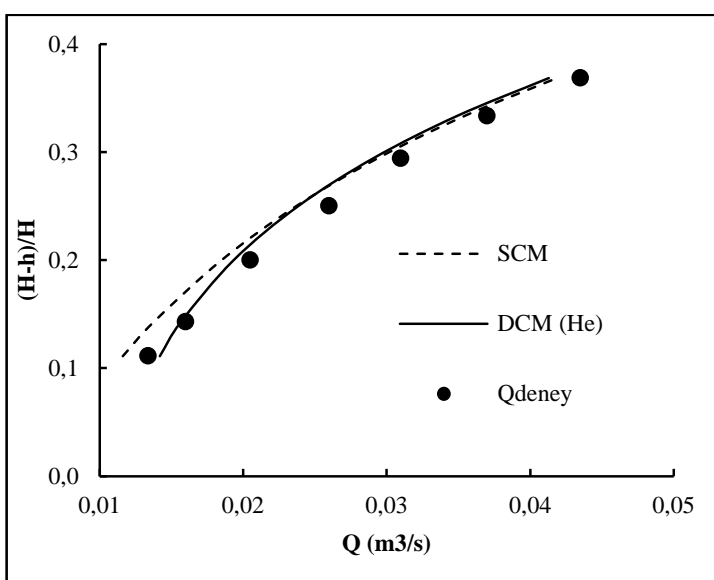

Şekil 3. A serisi için hesaplanan ve deneysel debi değerleri 


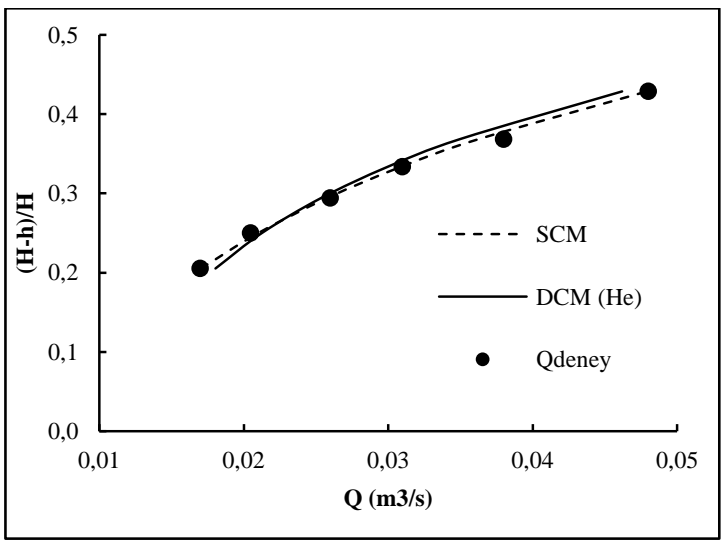

Şekil 4. B serisi için hesaplanan ve deneysel debi değerleri

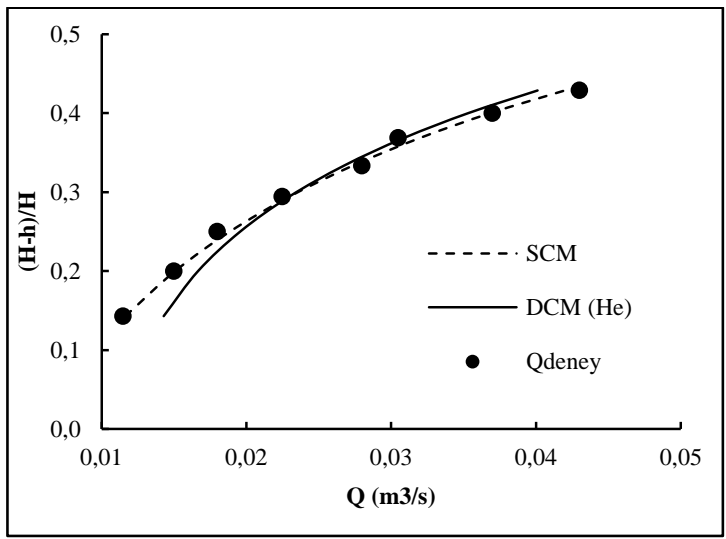

Şekil 5. C serisi için hesaplanan ve deneysel debi değerleri

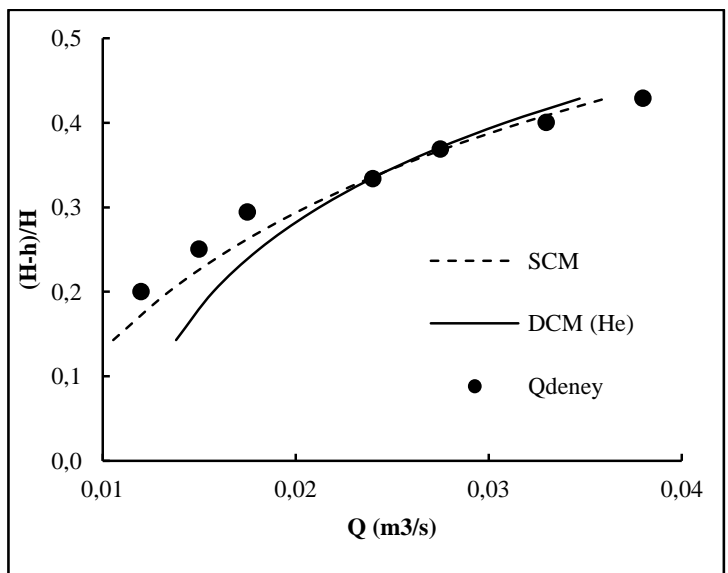

Şekil 6. D serisi için hesaplanan ve deneysel debi değerleri
Seviye-debi grafikleri incelendiğinde, pürüzlülüğün artması ile birlikte, su seviyesinin az olduğu durumlarda DCM (He) metodunun deneysel verilerin altında kaldığı, Şekil 5 ve Şekil 6'da görüldüğü üzere $(\mathrm{H}-\mathrm{h}) / \mathrm{H}=0,3$ değerinden itibaren deneysel verilerle uyum içerisinde olduğu görülmüştür. SCM metodu ise genel anlamda bütün grafiklerde deneysel verilerle paralellik arz etmektedir.

\section{SONUÇLAR}

Bileşik kesitli kanal modelinin debi hesabında $\mathrm{SCM}$ ve DCM metotları uygulanmıştır. Bu metotlar bir deneysel veriye uygulanmış ve hesap debileriyle deneysel debi değerleri karşılaştırılmıştır. Bileşik kesitli kanalda DCM metodunda He yöntemi, $\mathrm{V}$ (düş̧ey) ve $\mathrm{D}$ (diyagonal) yöntemlerine göre daha iyi sonuç vermiştir. Bununla birlikte SCM metodunun DCM metoduna göre daha az hata vermesi sebebiyle, SCM metodunun bileşik kesitli kanalların debisinin hesabında kullanılmasının daha uygun olduğu sonucuna varılmıştır.

\section{KAYNAKLAR}

1. Seçkin, G., 2004. A comparison of onedimensional methods for estimating discharge capacity of straight compound channels. Canadian Journal of Civil Engineering, 31, 619-631.

2. Rice, C.E., 1974. Hydraulics of Main Channel Floodplain Flows. Research Project Technical Completion Report, Oklahoma State University, USA.

3. Posey, C.J.F., 1967. Computations of Discharge Including Overbank Flow. Civil Engineering, ASCE, 37 (4), 62-63.

4. James, M., Brown, B.J., 1977. Geometric Parameters that Influence Floodplain Flow. US Army Engineers Waterways Experiment Station, Vicksburg, MS.

5. Myers, W.R.C., 1987. Velocity and Discharge in Compound Channels. Journal of Hydraulic Engineering-ASCE, 113, 753-766.

6. Tokyay, N.D., 1994. Computation of Discharge and Critical Depth in Compound Channels. $2^{\text {nd }}$ 
International Conference on River Flood Hydraulics, 22-25 March, York, England.

7. Sturm, T.W., Sadiq, A., 1996. Water Surface Profiles in Compound Channel with Multiple Critical Depths. Journal of Hydraulic Engineering-ASCE, 122, 703-709.

8. Myers, W.R.C., Lyness, J.F., Cassells, J., 2001. Influence of Boundary Roughness on Velocity and Discharge in Compound River Channels. Journal of Hydraulic Research, 39(3): 311-319.

9. Atabay, S.A., Knight, D.W., 2002. The Influence of Floodplain Width on the Stagedischarge Relationship for Compound Channels. River Flow 2002, Proceeding of International Conference on Fluvial Hydraulics, Louvain-la- Neuve, Belgium, September, Vol. 1, 197-204, Balkema.

10. Cebe, K., 2002. Farklı Girişim Alanları Yaklaşımlarına Göre Taşkın Yatağı Bulunduran Bileşik Kesitli Kanallarda Debi Hesap Yöntemlerinin İrdelenmesi. Yüksek Lisans Tezi, Gazi Üniversitesi, Ankara.

11. Özbek, T., Koçyiğit, M.B., Koçyiğit, Ö., Cebe, K., 2004. Comparison of Methods for Predicting Discharge in Straight Compound Channels Using the Apparent Shear Stress Concept. Journal of Engineering and Environmental Sciences, 28(2), 101-109.

12. Manning, R., 1889. On the Flow of Water in Open Channels and Pipes. Trans. Institution of Civil Engineers of Ireland, 20, 161-207.

13. Yuen, K.W.H., 1989. A Study of Boundary Shear Stress, Flow Resistance and Momentum Transfer in Open Channels With Simple and Compound Trapezoidal Cross Sections. PhD thesis, The University of Birmingham, UK.

14. Lotter, G.K., 1933. Considerations on Hydraulic Design of Channels With Different Roughness of Walls. Trans. All Union Scientific Research. Institute of Hydraulic Engineering, Leningrad, 238-241 (in Russian).

15. Sellin, R.H.J., 1964. A Laboratory Investigation into the Interaction Between the Flow in the Channel of a River and That Over its Flood Plain. La Houille Blanche, 7, 793-802.

16. Yen, C.L., Overton, D.E., 1973. Shape Effects on Resistance in Flood Plain Channels. Journal of the Hydraulics Division, ASCE, 99 (1), 219238.

17. Myers, W.R.C., 1978. Momentum Transfer in a Compound Channel. Journal of Hydraulic Research, IAHR, 16 (2). 139-150.

18. Knight, D. W., Shiono, K., 1996. River Channel and Floodplain Hydraulics. Floodplain Processes, (Eds Anderson, Walling and Bates), Chapter 5, J. Wiley, 139-181.

19. Knight, D.W., Yuen, K.W.H., Al-hamid, A.A.I., 1994. Boundary Shear Stress Distributions in Open Channel Flow. Mixing and Transport in the Environment, John Wiley $\&$ Sons.

20. Wormleaton, P.R., Hadjipanos, P., 1985. Flow Distribution in Compound Channels. Journal of Hydraulic Engineering-ASCE, 111, 357- 361.

21. Wormleaton, P.R., Allen, J., Hadjipanos, P., 1982. Discharge Assessment in Compound Channel Flow. Journal of the Hydraulics Division-Proc. of ASCE, 108, 975-994. 
